\title{
Rapid selection of a representative monitoring location of soil water content for irrigation scheduling using surface moisture-density gauge
}

\author{
Ibrahim Mubarak*, Mussadak Janat, Mohsen Makhlouf, and Altayeb Hamdan \\ Department of Agriculture, Atomic Energy Commission of Syria, P.O. Box 6091, Damascus, Syria
}

Received April 11, 2016; accepted October 17, 2016

\begin{abstract}
A b s t r a c t. Establishing a representative monitoring location of soil water content is important for agricultural water management. One of the challenges is to develop a field protocol for determining such a location with minimum costs. In this paper, we use the concept of time stability in soil water content to examine whether using a short term monitoring period is sufficient to identify a representative site of soil water content and, therefore, irrigation scheduling. Surface moisture-density gauge was used as a means for measuring soil water content. Variations of soil water content in space and time were studied using geostatistical tools. Measuring soil water content was made at 30 locations as nodes of a $6 \times 8 \mathrm{~m}$ grid, six times during the growing season. A representative location for average soil water content estimation was allocated at the beginning of a season, and thereafter it was validated. Results indicated that the spatial pattern of soil water content was strongly temporally stable, explained by the relationship between soil water content and fine soil texture. Two field surveys of soil water content, conducted before and after the 1st irrigation, could be sufficient to allocate a representative location of soil water content, and for adequate irrigation scheduling of the whole field. Surface moisture-density gauge was found to be efficient for characterising time stability of soil water content under irrigated field conditions.

K e y w o r d s: spatial variability, time stability, geostatistics, clay loam soil, wheat
\end{abstract}

\section{INTRODUCTION}

Spatial variability of soil water content $(S W C)$ represents a major challenge for agricultural water management, especially irrigation scheduling, because of the difficulty in obtaining measurements representing the average status of a field (Van Pelt and Wierenga, 2001). When an agricultural field is repeatedly surveyed for $S W C$, the pattern of spatial structure of $S W C$ does not change over time at a certain probability. In other words, locations can be often identified where the time series of $S W C$ is either constantly larger or constantly lower than the time series of the mean value. This phenomenon is called time stability or temporal stability in soil moisture spatial patterns (Chen et al., 1995; Hu et al., 2013; Tallon and Si, 2003; Van Pelt and Wierenga, 2001; Vachaud et al., 1985). Its presence has been routinely observed in widely different environments, and most studies have attributed such phenomena to various factors including soil texture, topography, vegetation, and climate (Brocca et al., 2009; Gomez-Plaza et al., 2001; Grayson and Western, 1998; Hu et al., 2013; MunozPardo et al., 1990).

One of the consequences of time stability in soil water spatial patterns is that one or more locations can often be identified that have a time series of $S W C$ very similar to the time series of the average $S W C$ estimation for the study area (Hu et al., 2013). The most important application of this feature for agricultural water management could be to adopt such locations for effective site-specific management of soil water through irrigation. Once representative locations are allocated, only few $S W C$ sensors at those locations are needed to regularly monitor the average $S W C$ across the agricultural field and, therefore, to mange irrigation water in terms of how much and when to irrigate.

Although information on time stability of $S W C$ has been widely documented, several scientific questions need more insight (Grayson and Western, 1998; Kachanoski and de Jong, 1988; Martinez-Fernandez and Ceballos, 2005; Mubarak et al., 2010; van Pelt and Wierenga, 2001). The

\footnotetext{
*Corresponding author e-mail: ascientific1@aec.org.sy
} 
use of time stability of $S W C$ requires the selection of the best time to identify such locations representing the mean field behaviour (Guber et al., 2008; Martinez-Fernandez and Ceballos, 2005; Grayson and Western, 1998). Grayson and Western (1998) pointed out that the observation time span has to be split into two periods: a training period, during which the best locations for representing the average soil water patterns are identified, then a validation period for testing the best locations. According to Martinez-Fernandez and Ceballos (2005), one year (a complete seasonal cycle) is recommended as a training period for both small (of $\left.0.62 \mathrm{~km}^{2}\right)$ and large $\left(1285 \mathrm{~km}^{2}\right)$ catchments with a complex vegetation cover. This is to say that an intensive measurement of $S W C$ over time is needed before a representative location can be allocated. These long term monitoring periods are probably specific for the location and spatial scale of their study sites. However, Guber et al. (2008) reported that obtaining good locations for the average water content estimation across their study area (6 ha) could be accomplished during one month. Therefore, the challenge is to develop a sampling strategy for establishing a representative location for the field average $S W C$ with a minimum cost in time, money and efforts. In addition, for irrigation scheduling purposes, it is desirable that the representative location could be pre-identified at the beginning of the growing season. Thus, the short term monitoring duration to identify a representative location for an average $S W C$ estimation could be feasible and recommended. That is to say, rapid and reliable assessment of the field average $S W C$ is an urgent need to determine the representative locations and, therefore, irrigation scheduling.

For many years, neutron probe technology has been used worldwide for regular monitoring of soil water status and for studies of spatial variability of $S W C$ (Gao and Sha, 2012; Haverkamp et al., 1984; Hu et al., 2009; Jansson, 1999; Vachaud et al., 1985; Vauclin et al., 1984). Unfortunately, near-surface measurement of soil moisture is a major problem with neutron moisture meter (Chanasyk and Naeth, 1996), particularly when the target soil layer is the surface tilled one. Moreover, the need for access tubes installed in the soil and to determine the bulk density using another technique for probe calibration can be considered as limitations. However, the surface moisture-density gauge (neutron/gamma technique) can overcome such problems. It operates with no need for any access tube and can determine both the wet bulk density and water content of topsoil (up to $30 \mathrm{~cm}$ ) as accurately as the standard core sampling procedure. Moreover, this instrument offers the advantage of quickly collecting a large number of soil measurements. It greatly reduces the labour of physical soil sampling and sample processing. Being nondestructive, it allows repeat sampling in the same positions (Jansson, 1999; Rousseva et al., 1988; Tominaga et al., 2002). Due to the described advantages, this instrument has recently become more popular for routine evaluation of topsoil water and bulk density in large agricultural enterprises (Tominaga et al.,
2002). But to our knowledge, there are no reports on using this gauge for regular monitoring of topsoil moisture content for the purposes of irrigation scheduling, especially for shallow rooted crops, or for studying spatial variability and time stability of $S W C$ under agricultural fields.

For a deeper insight into these two questions, ie the need of short term monitoring duration to select a representative location for field average $S W C$ estimation, and the contribution of the surface moisture-density gauge in the studies of spatial and temporal variability in agricultural fields, and to contribute to existing knowledge on time stability in $S W C$ patterns, the topsoil water contents were monitored at 30 measurement locations using an in-situ calibrated surface moisture-density gauge under irrigated wheat field conditions, on six dates covering the growing season range of soil moisture variations. Two observation dates, ie before and after the 1st irrigation event, representing two different soil moisture status (dry and wet), were used to identify the best location for representing the average $S W C$ estimation, and therefore for irrigation scheduling. Then, the six observation dates ie the time series of the six data sets of $S W C$ measurements covering the growing season, were used to validate the selected representative location.

Therefore, the objectives of this study were (i) to test the possibility of selecting a representative location for the field average $S W C$, and therefore, irrigation scheduling, using a short term monitoring period at the beginning of growing season, and (ii) to assess the efficacy of surface moisture-density gauge in characterising the spatial variability and time stability of topsoil moisture under irrigated field conditions.

\section{MATERIALS AND METHODS}

Field experiments were carried out on a 0.25 -ha field cropped with winter wheat (Triticum aestivum L.) at the Deir Al-Hajar Agricultural Experiment Station, Damascus, Syria $\left(33^{\circ} 20^{\prime} \mathrm{N}, 36^{\circ} 26^{\prime} \mathrm{E}\right.$, altitude $\left.600 \mathrm{~m}\right)$, for the cultivation season 2011-2012. Some climatic data for the studied field during the growing season are given in Table 1. The soil is classified as a clay loam. Average volumetric soil water contents at field capacity $(F C)$ and wilting point $(W P)$ are 0.35 and $0.18 \mathrm{~m}^{3} \mathrm{~m}^{-3}$, respectively. Average soil bulk density is $1.4 \mathrm{~g} \mathrm{~cm}^{-3}$.

At the end of October, the field was ploughed to a depth of $35 \mathrm{~cm}$ with a mouldboard plow. In mid-November, winter wheat was sown with row spacing of $20 \mathrm{~cm}$ and plant density of $200 \mathrm{~kg} \mathrm{ha}^{-1}$. The total amount of fertilisers applied was $230 \mathrm{~kg}$ urea ha- ${ }^{-1}$ and $100 \mathrm{~kg} \mathrm{P}_{2} \mathrm{O}_{5} \mathrm{ha}^{-1}$. For the purpose of irrigation scheduling, a representative site for average soil moisture estimation was pre-selected at the beginning of the growing season (detailes about selected site will be discussed later). On the basis of the management allowed depletion method (MAD), irrigation was applied when the topsoil water content measured in the pre-identified representative site reached $60-70 \%$ of field capacity. That is to 
T a b l e 1. Some climatic data during the growing season (2011-2012) of the experimental site

\begin{tabular}{|c|c|c|c|c|c|c|c|}
\hline Variable & November & December & January & February & March & April & May \\
\hline Minimum temperature $\left({ }^{\circ} \mathrm{C}\right)$ & 4.0 & 0.4 & 2.4 & 4.9 & 3.5 & 10.3 & 13.8 \\
\hline Maximum temperature $\left({ }^{\circ} \mathrm{C}\right)$ & 17.9 & 16.5 & 13.1 & 14.4 & 18.3 & 27.7 & 31.0 \\
\hline Relative air humidity (\%) & 53 & 67 & 70 & 65 & 51 & 42 & 36 \\
\hline $\mathrm{ET}_{0}\left(\mathrm{~mm} \mathrm{day}^{-1}\right)$ & 2.1 & 1.3 & 1.4 & 2.2 & 4.1 & 6.4 & 8.5 \\
\hline Precipitation (mm) & 11.3 & 5.2 & 39.8 & 16.5 & 26.7 & 1.0 & 0 \\
\hline
\end{tabular}

say, $30-40 \%$ of $F C$ was allowed to be depleted from the soil before the next irrigation. The first irrigation event of $40 \mathrm{~mm}$ was applied to the crop at sowing to provide suffiecient moisture for seed germination and seedling. Surface irrigation system with relatively small level basins was adopted. Water was delivered through plastic pipes to each basin to enhace irrigation practices. The crop was harvested at the end of May.

Troxler Model 3430 surface moisture-density gauge used herein is equipped with two radioactive sources: a gamma-emitter, for the determination of soil bulk density, and a neutron source, emitting fast neutrons for the water content determination. The count ratio $(C R(D))$, obtained by dividing the amount of detected gamma radiation by the amount determined in a standard block, is used to calculate the wet bulk density $(W D)$. The water content is determined using the neutron probe technique, in which fast neutrons emitted by the source penetrate the soil. In connection with collisions with hydrogen nuclei in the soil, the neutrons become thermalised (or slowed) and are counted by a neutron detector. The counts obtaind are directly proportional to the amount of hydrogen/moisture present in the soil: the larger the amount of thermalised neutrons the higher the soil water content. The counts are related to a standard count obtained in a reference block, and the quotient obtained by dividing the recorded count by the standard count is called the count ratio $(C R(W))$.

The gauge has one rod which can be lowered into the soil to the desirable depth, in $5 \mathrm{~cm}$ intervals, down to a maximum depth of $30 \mathrm{~cm}$. The gamma source is located in the tip of rod, and the gamma ray detector is located in the gauge base to measure the radiation emitted by the source rod. Tow modes of operation can be used to measure soil bulk density: direct transmission and backscattering of gamma radiation, depending on the required depth of measurement. The neutron source and detector, used for counting the thermalised neutrons, are located in the gauge base. The $S W C$ measurement depth varies according to the moisture content of soil and decreases with increasing water content. For a volumetric $S W C$ range of 0.18 to $0.35 \mathrm{~m}^{3} \mathrm{~m}^{-3}$, the measurement depth is about 313 to $204 \mathrm{~mm}$, respectively, according to the equation offered by Kristensen (1973). The sensing depth seems to be large enough for the determination of moisture in the topsoil layer.
Surface moisture-density gauge was in-situ calibrated before its use in this study. While there was no need to correct $W D$ given by the gauge (Jansson, 1999), the water content readings were corrected before calculating the dry bulk density $(D D)$. For that, three plots of $2 \times 2 \mathrm{~m}$ each surrounded by dikes from all sides were prepared. To have a wide range in water content, one of these plots received a depth of $20 \mathrm{~cm}$ of water, while a depth of $10 \mathrm{~cm}$ of water was added to the second one. The third was maintained air dry. Measurements of calibration were conducted $48 \mathrm{~h}$ after adding water. In each plot, five replications were carried out to achieve gauge readings and soil samples. Once the probe was lowered to the depth of $30 \mathrm{~cm}$, the measurements were started. The length of measurement period, which is adjustable, was $1 \mathrm{~min}$. The gamma-ray direct transmission mode was used in this study to measure the average density of the soil between 0 and $30 \mathrm{~cm}$ (from the surface to the source depth ). In the same sites of gauge readings, soil cores $(0-30 \mathrm{~cm})$ were taken in order to estimate gravimetric soil water content $\left(\theta_{m}\right)$ by the oven-dry method $\left(24 \mathrm{~h}\right.$ at $\left.105^{\circ} \mathrm{C}\right)$.

Volumetric soil water content $(\theta)$ in a soil sample was determined using the following equation:

$$
\theta=\frac{W D \theta_{m}}{1+\theta_{m}},
$$

where: $\theta$ and $\theta_{m}\left(\mathrm{~m}^{3} \mathrm{~m}^{-3}\right)$, and $W D\left(\mathrm{~g} \mathrm{~cm}^{-3}\right)$. Then, $D D$ was calculated by subtracting $\theta$ from $W D$.

The linear relationship between water content and count ratio for the neutrons was used to establish regression equation with volumetric $S W C$ determined by soil coring $(\theta)$ as the dependent variable and the corresponding count ratio $C R(W)$ obtaind using the gauge as the independent variable, using the 15 pairs of field calibration data.

Measurements of SWC using the in-situ calibrated surface moisture-density gauge were carried out adopting a regular monitoring grid of 30 measurement locations, each separated by $6 \times 8 \mathrm{~m}$ intervals (Fig. 1). Six data sets from $S W C$ measurements (W1-W6) were acquired at six different dates at the 30 pre-selected locations. W1 and W2 were carried out at the beginning of the season. W1 was taken just before applying the 1st irrigation event (on the 


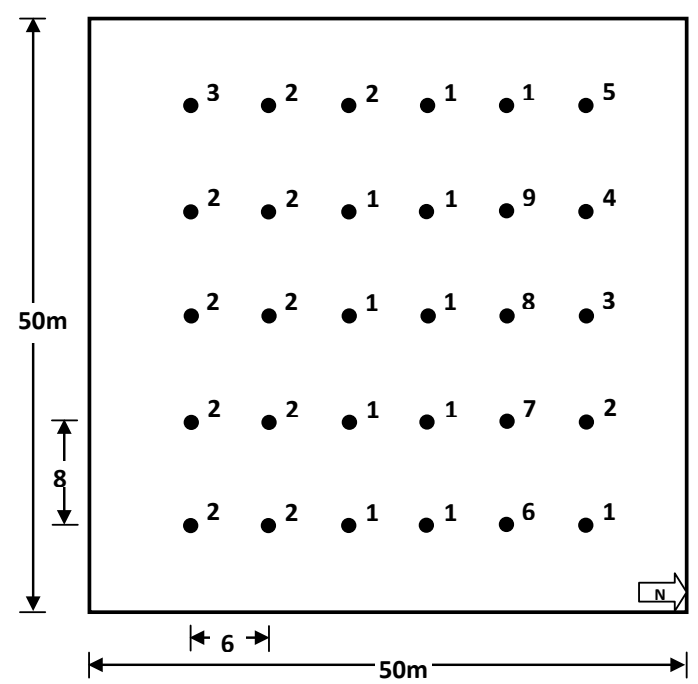

Fig. 1. Scheme of the studied field with measurement and sampling locations (marked is the location number).

planting day), representing low soil moisture (dry soil). The second one (W2) was taken a few days later, representing high soil moisture close to the field capacity (wet soil). The others (W3, W4, W5 and W6) were made in January, February, March, and April, respectively, in order to cover the growing season range of soil moisture variations. These six data sets were used to identify the representative location of average $S W C$ estimation, Since it was desirable that the representative location was pre-identified at the beginning of the season in order to schedule irrigation events, the sampling strategy proposed herein suggested using the first two data sets of $S W C$ measurements, ie W1 and $\mathrm{W} 2$, to select the representative site for average field $S W C$. Then, the six observation dates ie the time series of the six data sets of $S W C$ measurements covering the whole growing season, were used to validate the selected representative location.

Other measurements of $S W C$ using the in-situ calibrated surface moisture-density gauge were regularly carried out in the pre-selected representative location in order to schedule irrigation events for the whole field, where irrigation was applied when the topsoil water content reached $60-70 \%$ of $F C$ as noted above.

On planting day, disturbed soil samples were taken at the 30 nodes of the $6 \times 8 \mathrm{~m}$ grid superimposed on the grid of 30 pre-selected locations, to determine the textural components of topsoil $(0-30 \mathrm{~cm})$ using the hydrometer technique.

Measured variables were analysed using standard statistics to obtain their mean and coefficient of variation values. The normality of data frequency distribution was tested using the Kolmogorov-Smirnov test (Webster, 2001).
The spatial dependence and spatial structure of the measured variables were quantified using Geostatistics. The spatial structure of each variable was identified by the semivariogram using the Variowin program model (Pannatier, 1996). The experimental semivariogram $\gamma(l)$ was estimated as:

$$
\gamma(l)=\frac{1}{2 N(l)} \sum_{i=1}^{N(l)}\left[z\left(r_{i}\right)-z\left(r_{i}+l\right)\right]^{2}
$$

where: $N(l)$ is the number of pairs separated by lag distance, $l ; z\left(r_{i}\right)$ and $z\left(r_{i}+l\right)$ are measured values at locations $r_{i}$ and $r_{i+l}$, respectively. If the semivariogram increases with distance and stabilises at the $a$ priori variance value, it means that the variable under study is spatially correlated and all neighbouring sites within the correlation range can be used to interpolate values where they were not measured. Experimental semivariograms were normalised by dividing each semivariance value by the experimental variance value (Isaaks and Srivastava, 1989; Vieira and Gonzalez, 2003; Vieira et al., 1983; Warrick et al., 1986.

The cross-semivariogram was also considered in order to investigate the spatial correlation between two variables, and was calculated as (Isaaks and Srivastava, 1989; Vauclin et al., 1983):

$$
\gamma_{12}(l)=\frac{1}{2 N(l)} \sum_{i=1}^{N(l)}\left[z_{1}\left(r_{i}\right)-z_{1}\left(r_{i}+l\right)\right]\left[z_{2}\left(r_{i}\right)-z_{2}\left(r_{i}+l\right)\right],
$$

where: $z_{1}\left(r_{i}\right)$ and $z_{2}\left(r_{i}\right)$ are the values of the 1 st and 2 nd variables at location $\mathrm{r}_{\mathrm{i}}$, respectively. $z_{l}\left(r_{i}+l\right)$ and $z_{2}\left(r_{i}+l\right)$ are their values at location $r_{i}+l$. The corresponding cross-semivariogram was normalised by the product of experimental standard deviations of the two variables.

Both spherical and exponential models were compared to select the best fitted model (data not shown) which fits the normalised experimental values of both semivariogram and cross-semivariogram. Empirical data were found to be best fitted by the spherical model.

The spherical model is defined by the following relation (Isaaks and Srivastava, 1989):

$$
\begin{aligned}
\gamma^{*}(l) & =C_{0}+C_{1}\left(1.5 \frac{l}{a}-0.5\left(\frac{l}{a}\right)^{3}\right) & & \text { for } l \leq a \\
& =C_{0}+C_{1}=C_{2} & & \text { for } l>a,
\end{aligned}
$$

where: $C_{0}$ is the nugget effect, $a$ is the range of spatial dependence and $C_{2}$ is the sill. Equation (4) was fitted to the experimental data by using least squares minimisation. The coefficient of determination $\left(\mathrm{R}^{2}\right)$ was calculated as an indicative goodness of fit. 
T a b l e 2. Descriptive statistical parameters of some soil properties

\begin{tabular}{|c|c|c|c|c|c|c|c|c|c|c|}
\hline \multirow{3}{*}{ Variable } & \multicolumn{4}{|c|}{ Particle size distribution (\%) } & \multicolumn{6}{|c|}{ Topsoil water content $\left(\mathrm{m}^{3} \mathrm{~m}^{-3}\right)$} \\
\hline & Clay & Fine silt & $\begin{array}{c}\text { Coarse } \\
\text { silt }\end{array}$ & Sand & \multirow{2}{*}{ W1 } & \multirow{2}{*}{ W2 } & \multirow{2}{*}{ W3 } & \multirow{2}{*}{ W4 } & \multirow{2}{*}{ W5 } & \multirow{2}{*}{ W6 } \\
\hline & $<2 \mu \mathrm{m}$ & $2-20 \mu \mathrm{m}$ & $20-50 \mu \mathrm{m}$ & $\begin{array}{l}0.05- \\
2 \mathrm{~mm}\end{array}$ & & & & & & \\
\hline Mean $(30)^{*}$ & 29.5 & 29.5 & 13.2 & 27.8 & 0.22 & 0.31 & 0.30 & 0.29 & 0.25 & 0.23 \\
\hline $\mathrm{CV}(\%)$ & 5.7 & 8.1 & 22.7 & 15.0 & 6.0 & 5.3 & 4.3 & 4.2 & 4.6 & 4.1 \\
\hline
\end{tabular}

*Test size, W1-W6 - data sets of soil water content measurements.

The representative location for average soil moisture estimation was identified using the principle of spatial variability and time stability of $S W C$ according to the principle developed by Vachaud et al. (1985). The first two data sets of $S W C$ measurements ie $\mathrm{W} 1$ and $\mathrm{W} 2$, measured before and after the 1st irrigation, representing two extreme situations of soil moisture, were used to identify the representative site. Then, the time series of the six data sets of $S W C$ measurements, covering the whole growing season, were used to validate the selected site.

The method used to evaluate the time stability, and therefore to select the representative location, concerns the difference $\Delta_{i j}$ between an individual determination of soil water content $\theta_{i j}$ at location $i(i=1-30)$ at time $j(j=1-2$, for only $\mathrm{W} 1$ and W2) and the mean soil water content $\bar{\theta}_{j}$ at the same time:

$$
\Delta_{i j}=\theta_{i j}-\bar{\theta}_{j}
$$

with

$$
\bar{\theta}_{j}=\frac{1}{30} \sum_{i=1}^{i=30} \theta_{i j}
$$

This corresponds to the relative difference $\delta_{i j}$ :

$$
\delta_{i j}=\frac{\Delta_{i j}}{\bar{\theta}_{j}} .
$$

Hence, for any location $i$ the time average $\bar{\delta}_{i}$, and the temporal standard diviation $\sigma\left(\delta_{i j}\right)$, can be calculated for the two data sets of $S W C$ measurements. A location where the mean relative difference was close to zero, and its temporal standard diviation was also relatively small, was selected and used as a representative location for average $S W C$ estimation (Hu et al., 2013; Vachaud et al., 1985).

In order to confirm the time stability and to validate the statistical representativity of selected location, the other data sets from $S W C$ measurements conducted at different dates during the growing season were used. Therefore, a time series of six data sets (W1-W6) was analysed using the the same criteria. In this case, Eqs (5) and (6) were ap- plied for the same locations $i(i=1-30)$ but at time $j(j=1-6$, for $\mathrm{W} 1$ to W6), and the temporal standard diviation $\sigma\left(\delta_{i j}\right)$ can be calculated for the six data sets.

\section{RESULTS AND DISCUSSION}

Firstly, field calibration curve relating the count ratio, $C R(W)$, obtaind using the surface moisture-density gauge, to volumetric soil water content $(\theta)$ was established. The intercept of straight line regression was 0.1037 and the slope was 0.667 with $\mathrm{R}^{2}=0.981(\mathrm{p}<0.0001)$.

Some statistical parameters (mean values and coefficients of variation, $C V$ ) are given in Table 2 for the six data sets of soil water content (W1-W6) measured on the 30 measuring locations, and for the particle size distribution determined on the same 30 locations. Data sets of soil textural components and soil water contents (W1-W6) were found to be normally distributed (KolgomorovSmirnov test). Particle-size distribution analysis showed that the soil classified as a clay loam soil contains on average $27.8 \%$ sand, $42.7 \%$ silt and $29.5 \%$ clay. The values of coefficients of variation $(\mathrm{CV})$ ranged from little $(5.7 \%)$ to middle $(22.7 \%)$ according to the classification described by Wilding (1985).

With the total number of observations, the pairs $N(l)$ (ranged from 98 to 184 pairs) for each lag in the semivariogram were much greater than the minimum required mentioned in the literature (about 30 pairs of points per lag) (Journel and Huijbregts, 1978; Mulla and McBratney, 2002). This enssures the reliability of the estimation of experimental data of semi-variances. The normalised experimental values of semi-variances were best fitted to the spherical model using Eq. (4), as shown in Fig. 2 for topsoil moisture measurements (W1-W6), and in Fig. 3 for textural components $(\mathrm{FS}+\mathrm{C}) \%$ (Fine silt plus clay contents, ie particle size less than $20 \mu \mathrm{m})$. The values of coefficient of determination $\left(R^{2}\right)$ were $0.85(p<0.01)$ and $0.98(p<0.001)$, respectively. The corresponding parameters: the nugget effect $C_{0}$, the sill $C_{2}$ and the range $a$ are presented in Table 3 . The following comments can be made:

- All data sets of studied variables presented strong spatial autocorrelations. This indicates the existence of spatial structures across the field. 


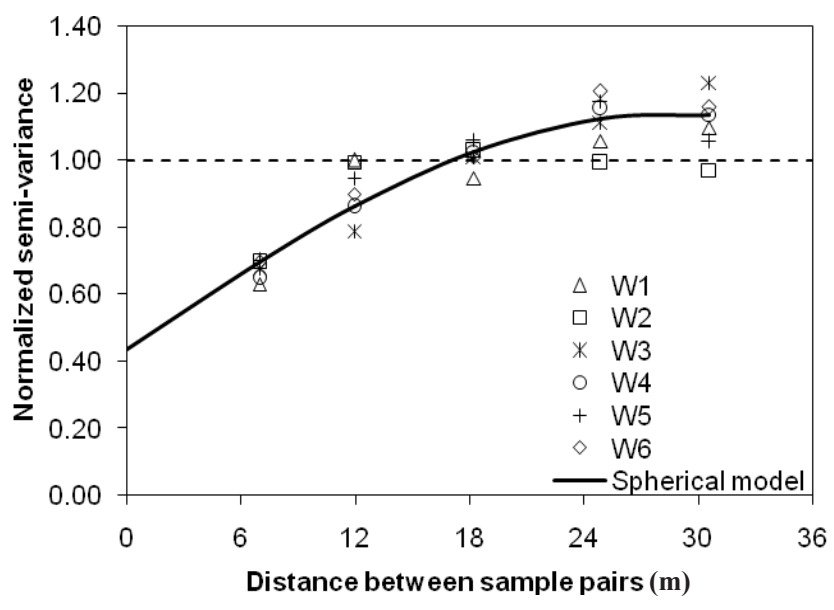

Fig. 2. Experimental (points) and fitted (solid line) spherical normalized semivariograms for all $S W C$ data sets covering the growing season (W1-W6).

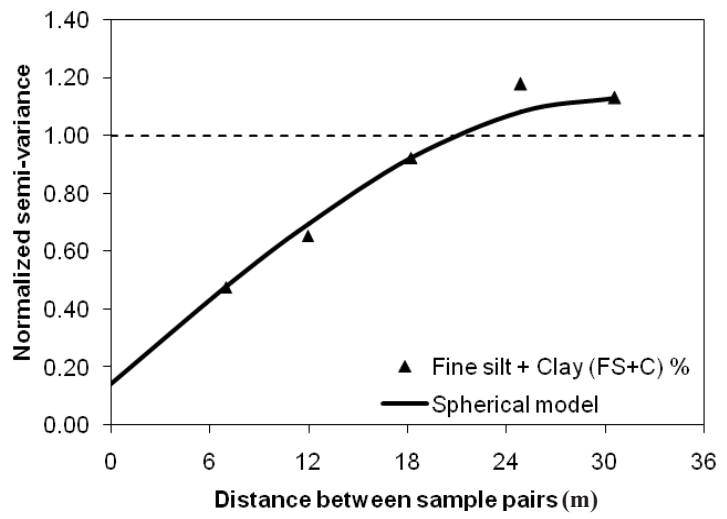

Fig. 3. Experimental (points) and fitted (solid line) spherical normalized semivariograms for fine silt and clay content.

- Although their mean values are different, all data sets of topsoil moisture measured at various dates (W1-W6) showed similar spatial structures (Fig. 2 and Table 2). This result shows the existence of a strong time stability of spatial structure of soil moisture measured using the surface moisture-density gauge.

- Relatively high values of nugget effect $C_{0}$ were observed. This could be attributed to both measurement errors and spatial microvariation occurring at distances shorter than the measurement interval $(6 \times 8 \mathrm{~m})$ (Mulla and McBratney, 2002).

- The range values were similar (from 20 to $30 \mathrm{~m}$ ). This indicates that the spatial patterns of variables are similar under the agro-pedo-climatic context of the field. A determinism tending to impose its own structure may be invoked (Munoz-Pardo et al., 1990).

- The normalised semivariograms presented sill values slightly greater than unity (as it should be from a theoretical viewpoint). The stability of semi-variance beyond the range highlights the lack of drift and indicates that

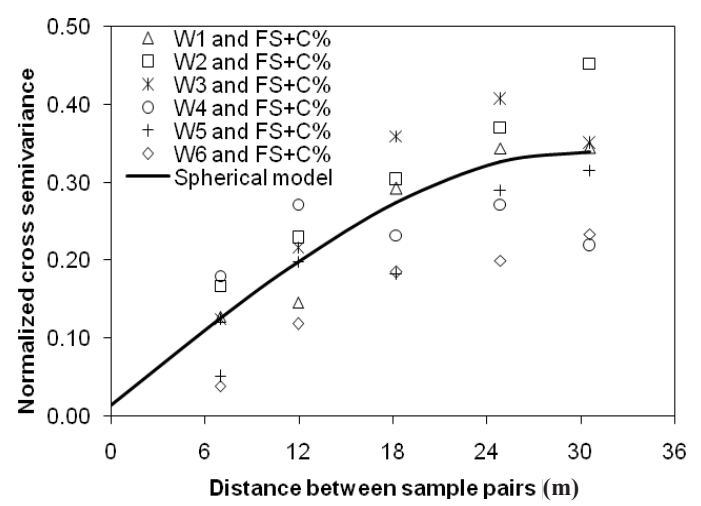

Fig. 4. Experimental (points) and fitted (solid line) spherical normalized cross-semivariograms between soil water contents (W1-W6) and fine silt and clay contents ( $\mathrm{FS}+\mathrm{C} \%$ ).

the dimensions of tested field seem to be large enough to describe the whole spatial variabilities of the evaluated variables.

The time stability of spatial structure of soil moisture could be related to the possible existence of a deterministic factor imposed by soil texture. As can be seen in Fig. 4, soil water content measured at any time (W1-W6) is strongly correlated with the percentage of fine fraction of soil texture $(\mathrm{FS}+\mathrm{C}) \%$ up to $30 \mathrm{~m}$ (Table 3). This value is indeed comparable to the ranges found for the two variables (Figs 2, 3, and Table 3). The nugget effect $C_{0}$ of the cross semivariogram was close to zero. The sign of the cross semivariance signifies a positive relationship between the two variables. Relating the soil texture to the time stability of spatial structure of $S W C$ was in agreement with the findings reported in several published studies (Mubarak et al., 2010; Munoz-Pardo et al., 1990). Munoz-Pardo et al. (1990) analysed the spatial variation of gravimetric water content at three dates of sampling. They found that the time stability of the spatial distribution of moisture may be explained by a determinism which was mainly imposed by soil texture. Mubarak et al. (2010) reported that the spatial correlations of soil hydraulic parameters after a 17-year period of repeated conventional agricultural practices of tillage and planting, appear to be temporally stabilised. They found that this time stability may be attributed to the soil textural properties which remain constant in time and to the structural properties which were constantly renewed by the cyclic agricultural practices.

The values of the relative time deviation from the mean $S W C$ measured before and after the first irrigation (W1 and W2), and its associated temporal standard deviation for each location of measurement, are given in Fig. 5, where the values of relative time deviations are sorted and ranked in ascending order $i e$ from the lowest value to the highest one. It can be seen that any given location either overestimated $(>0)$ or underestimated $(<0)$ the field average $S W C$ systematically regardless of the monitoring time. Also, the temporal standard deviation for any location is relatively small. 
T a b l e 3. Related parameters of spherical models fitted to experimental normalized semi-variances and cross semi-variances. $C_{0}, C_{2}$ and $a$ are the nugget effect, the sill and the range, and the values of determination coefficient $\left(\mathrm{R}^{2}\right)$, respectively

\begin{tabular}{lcccc}
\hline Variable & $C_{0}$ & $C_{2}$ & $a(\mathrm{~m})$ & $\mathrm{R}^{2}$ \\
\hline W (W1-W6) & 0.44 & 1.13 & 27.7 & $0.85(\mathrm{p}<0.01)$ \\
FS+C & 0.14 & 1.13 & 30.5 & $0.98(\mathrm{p}<0.001)$ \\
W and (FS+C)\%* & 0.01 & 0.33 & 30.0 & $0.60(\mathrm{p}<0.001)$ \\
\hline
\end{tabular}

*Corresponds to the cross-semivariogram between water content and fine textural component, W1-W6 - data sets of soil water content measurements, FS+C - fine silt plus clay content (particle size less than $20 \mu \mathrm{m}$ ).

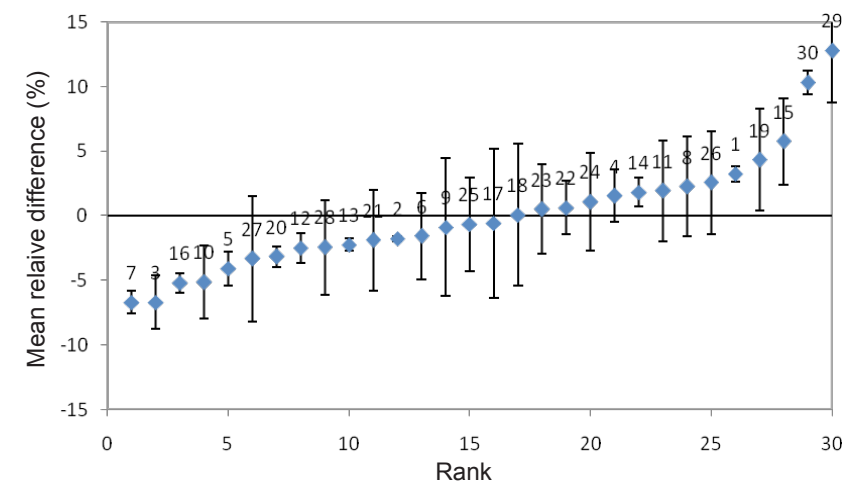

Fig. 5. Ranked time relative deviation from the mean spatial soil water content for the first two data sets (W1-W2) (before and after the 1st irrigation). Vertical bars correspond to associated temporal standard deviation. Numbers refer to measuring locations.

The results also show that locations \#7 and \#29 represented the dryest and the wettest sites, respectively. The $S W C$ in location \#7 was $6.7 \%( \pm 0.9 \%)$ smaller than the field average, whereas in location $\# 29$ it was $12.8 \%$ $( \pm 4.1 \%)$ greater than the field average. Of particular interest is the fact that for six locations $(9,17,18,22,23$ and $25)$, the mean relative differences were very close to zero (within $\pm 1 \%$ of the field average value), although deviations were of different values. Among these six locations, location \#22 represented the smallest value of uncertainty of $\pm 1.1 \%$ (time standard deviation). The measuring location \#22 appeared to be the best for estimating the average water contents and, as a result, it was selected and used as a representative site for average $S W C$ estimation and, therefore, field irrigation scheduling.

The time stability in the ranking of individual observations as defined by Vachaud et al. (1985) was tested by a time series analysis of the six data sets of water content observations covering the growing season (W1-W6). Figure 6 shows the values of relative time deviation from the mean $S W C$ and its associated temporal standard deviation for each measuring location. All values of relative time deviations are sorted and ranked in ascending order $i e$ from the lowest value to the highest one. As it is shown for these six data sets, the ranking of some measuring locations shows a weak time stability and they do not remain

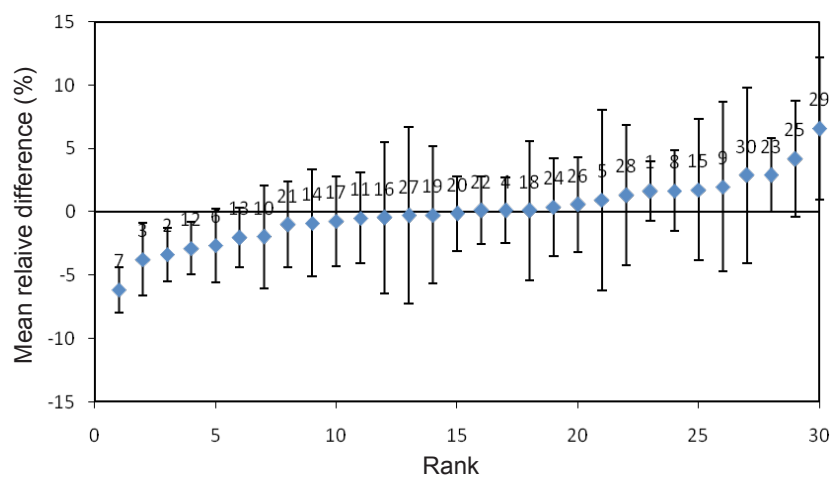

Fig. 6. Ranked time relative deviation from the mean spatial soil water content for all data sets (W1-W6). Explanations as in Fig. 5.

within the uncertainty domain of the mean value of soil water content. However, the results demonstrated the existence of a strong time statbility of particular individual locations characterised by the same parameter in the statistical distribution of the observations taken over the field. They showed that the location chosen to represent the mean value of the field water content (ie location \#22) maintained the same property during the growing season, where the mean relative difference was close to zero $(0.09 \%$ of the field average value), and its temporal standard diviation was also relatively small (of $\pm 2.67 \%$ ). Also, locations \#7 and $\# 29$, representing extreme values of the field water content, maintained the same properties during the growing season. They represented the dryest and the wettest sites, respectively. This result indicated that the surface moisturedensity gauge used in this work was an efficient means for studying the time stability of $S W C$ of cropped fields under irrigation conditions and, therefore, for identifying a representative location for estimating average soil moisture.

As mentioned above, regular field monitoring of topsoil moisture in the selected site at the beginning of growing season was used as a guide to schedule irrigation events of the whole tested field. To ensure certainty of the selected site (ie location \#22) whether it represents the crop water demand for the whole field or not, the crop water requirements which were calculated using the water balance 


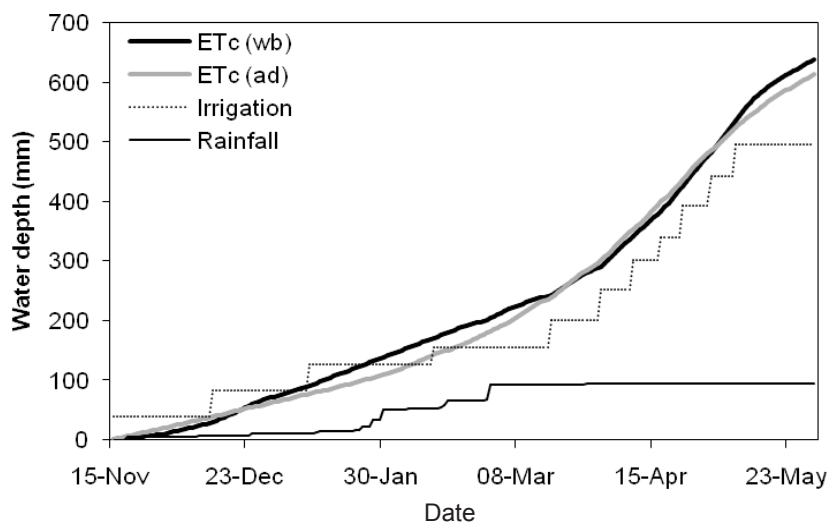

Fig. 7. Ranked time relative deviation from the mean spatial soil water content for all data sets (W1-W6). Explanations as in Fig. 5.

approach in the representative location were compared with those estimated from atmospheric parameters. In other words, the values of crop evapotranspiration calculated using the principle of water balance for a $30-\mathrm{cm}$ soil-layer thickness in the representative location (\#22) (denoted $\mathrm{ETc}(w b))$ were plotted jointly with those estimated based on atmospheric data (denoted ETc(ad)).

Assuming that the runoff and deep percolation were neglected, the other components of water balance approach, i.e., rainfall, irrigation water, and changes in topsoil water storage ( $\mathrm{mm}$ of water $/ 30 \mathrm{~cm}$ of soil), were measured over the time interval between two sequences of regular soil moisture measurements. The values of ETc(ad) were calculated by multiplying the daily reference evapotranspiration (ET0), calculated using the method of Penman-Monteith (FAO, 1998), by the crop coefficient (Kc). Values of Kc at each growth stage were obtained from FAO databases (FAO, 1998). The duration of the initial, development, midseason and late season growth stages were 20, 70, 70, and 30 days, respectively.

The values of $\operatorname{ETc}(\mathrm{wb})$ in the representative location were plotted against those of ETc(ad) (Fig. 7). Water inputs from rainfall and irrigation over the growing season are also shown. The changes over time in both $\operatorname{ETc}(w b)$ and ETc(ad) were similar throughout the growing season. Their cumulative values were about 638 and $613 \mathrm{~mm}$, respectively. The cumulative amount of irrigation water applied was $495 \mathrm{~mm}$, approximately equal to the crop water demand till termination (beginning of May), as shown in Fig. 7. This finding indicated that the measurement depth of SWC (about $30 \mathrm{~cm}$ ) using the surface moisture-density gauge seems to be large enough for an accurate evaluation of water temporal dynamics closer to the soil surface, where soil is subjected to evapotranspiration, rainfall, and irrigation events (Hupet and Vanclooster, 2002).

\section{CONCLUSIONS}

1. Two field surveys of soil water content at the beginning of growing season, representing two different soil water status ie before and after the 1st irrigation event, could be sufficient to select a representative monitoring location of soil water content.

2. Such monitoring location could be enough for adequate irrigation scheduling of the whole field.

Surface moisture-density gauge was found to be an efficient means for regular monitoring of soil water content under irrigated-wheat-field conditions, and for studying spatial variability and time stability of soil moisture.

Conflict of interest: Authors not declare conflict of interest.

\section{REFERENCES}

Brocea L., Melone F., Moramarco T., and Morbidelli R., 2009. Soil moisture temporal stability over experimental areas in Central Italy. Geoderma, 148, 364-374.

Chanasyk D.S. and Naeth M.A., 1996. Field measurement of soil moisture using neutron probes. Can. J. Soil Sci., 76, 317-323.

Chen J., Hopmans J.W., and Fogg G.E., 1995. Sampling design for soil moisture measurements in large field trials. Soil Sci., 159, 155-161.

FAO, 1998. Crop evapotranspiration: guidelines for computing crop requirements. Irrigation and Drainage Papers, No. 56. Roma, Italy.

Gao L. and Shao M., 2012. Temporal stability of soil water storage in diverse soil layers. Catena, 95, 24-32.

Gomez-Plaza A., Martínez-Mena M., Albaladejo J., and Castillo V. M., 2001. Factors regulating spatial distribution of soil water content in small semi-arid catchments. J. Hydrol., 253, 211-226.

Grayson R.B. and Western A.W., 1998. Towards areal estimation of soil water content from point measurements: Time and space stability of mean response. J. Hydrol., 207, 68-82.

Guber A.K., Gish T.J., Pachepsky Y.A., van Genuchten M.T., Daughtry C.S.T., Nicholson T.J., and Cady R.E., 2008. Temporal stability in soil water content patterns across agricultural fields. Catena, 73, 125-133.

Haverkamp R., Vauclin M., and Vachaud G., 1984. Error analysis in estimating soil water content from neutron probe measurements: 1. Local standpoint. Soil Sci., 137, 78-90.

Hu W., Shao M., Wang Q., and Reichardt K., 2009. Time stability of soil water storage measured by neutron probe and the effects of calibration procedures in a small watershed. Catena, 79, 72-82.

Hu W., Tallon L.K., Biswas A., and Si B.C., 2013. Time stability of soil water content. In: Advances in agrophysical research (Eds S. Grundas, A. Stepniewski). ISBN: 978-953-511184-9, InTech, DOI: 10.5772/3341.

Hupet F. and Vanclooster M., 2002. Intraseasonal dynamics of soil moisture variability within a small agricultural maize cropped field. J. Hydrol., 261, 86-101. 
Isaaks E.H. and Srivastava R.M., 1989. An Introduction to Applied Geostatistics. Oxford Univ. Press, New York, USA.

Jansson K.J., 1999. Comparison of density and water content determinations using soil cores and a dual probe density gauge. Int. J. Forest Eng., 10(2), 83-90.

Journel A.G. and Huijbregts C.J., 1978. Mining Geostatistics. Academic Press, London, UK.

Kachanoski R.G. and de Jong E., 1988. Scale dependence and the temporal persistence of spatial patterns of soil water storage. Water Resour. Res., 24, 85-91.

Kristensen K.J., 1973. Depth intervals and topsoil moisture measurement with the neutron depth probe. Nordic Hydrol., 4, 77-85.

Martinez-Fernandez J. and Ceballos A., 2005. Mean soil moisture estimation using temporal stability analysis. J. Hydrol., 312, 28-38.

Mubarak I., Angulo-Jaramillo R., Mailhol J.C., Ruelle P., Khaledian M., and Vauclin M., 2010. Spatial analysis of soil surface hydraulic properties: Is Infiltration MethodDependent? Agric. Water Manag., 97(10), 1517-1526.

Mulla D.J. and McBratney A.B., 2002. Soil spatial variability. In: Handbook of Soil Science (Ed. M.E. Sumner). CRC Press, London, UK.

Munoz-Pardo J., Ruelle P., and Vauclin M., 1990. Spatial variability of an agricultural field: geostatistical analysis of soil texture, soil moisture and yield components of two rainfed crops. Catena, 17, 369-381.

Pannatier Y., 1996. VARIOW, Software for Spatial Data Analysis in 2D. Springer Verlag, New York, USA.

Rousseva S.S., Ahuja L.R., and Heathman G.C., 1988. Use of a surface gamma-neutron gauge for in situ measurement of changes in bulk density of the tilled zone. Soil Tillag. Res., $12,235-251$

Tallon L.K. and Si B.C., 2003. Representative soil water benchmarking for environmental monitoring. Environ. Inform. Arch., 1, 581-590.
Tominaga T.T., Cássaro F.A.M., Reichardt K., Bacchi O.O.S., Oliveira J.C.M., and Timm L.C., 2002. On the use of surface neutron-gamma gauges to estimate soil water content. Appl. Radiat. Isot., 57, 369-374.

Vachaud G., Passerat de Silans A., Balabanis P., and Vauclin M., 1985. Temporal stability of spatially measured soil water probability density function. Soil Sci. Soc. Am. J., 49, 822-828

Van Pelt R.S. and Wierenga P.J., 2001. Temporal stability of spatially measured soil matric potential probability density function. Soil Sci. Soc. Am. J., 65, 668-677.

Vauclin M., Haverkamp R., and Vachaud G.. 1984. Error analysis in estimating soil water content from neutron probe measurements: 2. Spatial standpoint. Soil Sci., 137, 141-148.

Vauclin M., Vieira S.R., Vachaud G., and Nielsen D.R., 1983. The use of cokriging with limited field soil observations. Soil Sci. Soc. Am. J., 47, 175-184.

Vieira S.R. and Gonzalez A.P., 2003. Analysis of the spatial variability of crop yield and soil properties in small agricultural plots. Bragantia, Campinas, 62(1), 127-138.

Vieira S.R., Hatfield J.L., Nielsen D.R., and Biggar J.W., 1983. Geostatistical theory and application to variability of some agronomic properties. Hilgardia, 51, 1-75.

Warrick A.W., Myers D.E., and Nielsen D.R., 1986. Geostatistical methods applied to soil science. In: Methods of soil analysis. Part 1. (Ed. A. Klute) Agron. Monogr. 9, ASA and SSSA, Madison, WI, USA.

Webster R., 2001. Statistics to support soil research and their presentation. Eur. J. Soil Sci., 52, 331- 340.

Wilding L.P., 1985. Spatial variability: its documentation, accomodation, and implications to soil surveys. In: Soil Spatial Variability (Eds D.R. Nielsen, J. Bouma). Pudoc, Wageningen, the Netherland. 